\title{
$\$$ Research Square

\section{Gender differences in the association between body mass index and self-rated health among patients with hypertension: evidence from Rizhao City, China}

\section{Zhiqiang Feng}

Weifang Medical University

Longde Zhou

Weifang Medical University

Zixuan Zhao

Weifang Medical University

Changhai Tang

Weifang Medical University

Xingmin Chen

Weifang Medical University

Zhongming Chen

Weifang Medical University

Mengna Dai

Weifang Medical University

Wenqiang Yin ( $\nabla$ yinwenq1969@163.com )

Weifang Medical University

Research article

Keywords: BMI, SRHMS, Hypertension, Gender, Obesity

Posted Date: January 6th, 2020

DOI: https://doi.org/10.21203/rs.2.20078/v1

License: (1) (1) This work is licensed under a Creative Commons Attribution 4.0 International License.

Read Full License 


\section{Abstract}

Objective: This study is designed to examine the association between body mass index (BMI) and selfrelated health (SRH), and to explore gender differences in BMI-SRH association among hypertensive patients further. Methods: The status of SRH in 1219 hypertensive patients over 18 years old was analyzed by the multi-item self-rated health measurement scale (SRHMS). Chi-square test and t-test were used to analyze BMI and SRHMS status of hypertensive patients, the logistic regression analysis was used to explore the association between BMI and SRHMS of male and female separately after controlling for potential confounders, and to assess gender differences on the relationship between $\mathrm{BMI}$ and SRHMS. Results: The prevalence of underweight in hypertensive patients was $1.6 \%$, normal weight was $33.0 \%$, overweight was $45.9 \%$, and obese was $19.5 \%$. And the SRHMS of very good, good, fair, bad, and very bad were $20.2,15.4,29.1,12.5$, and $22.8 \%$, respectively. After controlling potential confounders, we found that underweight, overweight and obese had a negative impact on female's SRHMS. Underweight had a negative impact on male, but obesity had a positive impact on male's SRHMS. Besides, this study did not find that overweight had a statistically significant effect on male SRHMS. Conclusion: In this cross-sectional study, we found a gender differences on association between BMI and SRHMS among hypertensive patients. Overweight and obesity had a negative impact on female's SRHMS after adjusting for other influential factors, but not for male. Gender differences should be considered when developing weight and hypertension management programs, especially in women.

\section{Introduction}

Hypertension is one of the most common noncommunicable chronic diseases[1], which is becoming a major public health problem that challenges the whole world[2]. The global prevalence rate of hypertension is expected to rise to $29 \%$, with 1.56 billion people suffering from hypertension by the year 2025[3]. Hypertension also causes a massive burden in China, and it has been identified as the second leading health risk factor in China[4, 5]. There are a large number of hypertensive patients in China, and uncontrolled hypertension is a powerful risk factor of cardiovascular disease, efforts to detect and control hypertension has been a continuously important issue to public health.

Concurrently, obesity has been increasing rapidly, which is recognized as the major and modifiable risk factor for hypertension, being responsible for $20-30 \%$ of disease cases[6]. Obesity is a universal disease of increasing prevalence with alarming proportions worldwide, especially in the developing nations[7-10]. Prevalence of obesity and hypertension can predispose one to various other health complications such as diabetes, renal failure, and cardiovascular disease[11]. Body mass index (BMI) as an anthropometric index is used most frequently to define different obesity categories among various populations[12], and it has been widely used in the study of obesity-related hypertension[13, 14].

Self-rated health ( $\mathrm{SRH})$ is a subjective assessment of individual health status, also known as subjective health or self-assessed health[15]. SRH is considered to be an appropriate and effective indicator of service needs and intervention outcomes[16, 17], and can predict individual health outcomes[18]. 
However, studies have shown that single SRH as a dependent variable is not specific enough[19, 20]. WHO defines health as a multidimensional concept that includes physical health, mental health and social well-being[20], this concept is created out of many factors subjectively that include health behaviors, general physical functioning and specific health situations. Thus, it is impractical for a singleitem question to capture the characteristics of health conditions fully. Based on this, some researchers have developed the multiple-item self-rated health measurement scale (SRHMS) according to the health characteristics of Chinese people and applied it to SRH practice[21, 22].

Prior studies exploring the association between $\mathrm{BMI}$ and $\mathrm{SRH}$, some have found $\mathrm{U}$ shaped relationship between them[23, 24], some studies have proved that BMI and SRH varies significantly across ages and sexes[25]. However, Chinese research in this field is insufficient. So far, some studies have explored the association between them, most of them have been conducted in western or other high-income countries. Furthermore, most of the studies are aimed at healthy people, and few of them are aimed at hypertensive patients.

A better understanding of the $\mathrm{BMI}$ and $\mathrm{SRH}$ mechanisms will help in the design of more targeted and appropriate interventions. To do so, we have the following specific objectives. Firstly, we will analyze the SRHMS and BMI status of hypertensive patients. Secondly, we will examine the gender difference in the association between BMI and SRHMS.

\section{Methods}

Study site

This study was conducted in Rizhao City, Shandong Province, China. Rizhao City is located in the southeast of Shandong Province, and it's a coastal city in the east near the Pacific Ocean. It mainly includes 4 districts, Donggang, Lanshan, Juxian and Wulian, with altogether 55 townships. In this study, according to the principle of multi-stage stratified random sampling, two districts of Lanshan and Wulian were selected randomly considering the GDP level (high and low) and location (coastal and inland). Then, 4 communities and 4 villages were selected from each sampling district. Thus, we selected 8 urban communities and 8 rural villages in total. Figure 1 shows the location of the two study sites.

Data collection

The survey was conducted from March to April in 2019, a set of standardized questionnaires was used to collect data in the community health service institutions where the respondents were located. The questionnaires included sociodemographic information, SRHMS status, health-related behaviors, and blood pressure values. All participants (over 18 years of age) were interviewed face to face by trained nurses in isolated rooms. To ensure the quality, the completed questionnaires were carefully checked by the quality supervisor after the interview. In total, 4390 eligible participants were included in this study. 
Trained nurses performed blood pressure measurements, and the participants measured the blood pressure of the right arm using a sphygmomanometer after sitting for 15 minutes. Each subject's blood pressure was measured three times, and the average of the last two times was taken as the blood pressure value. Hypertension was defined based on the JNC 7 guidelines (SBP $\geq 140$ or DBP $\geq$ $90 \mathrm{mmHg}$ ). Considering other diseases that may affect SRH (cancer, mental illness, metabolic disorders, etc.), nurses asked respondents about their past disease history and excluded them from the study.

\section{Variables}

Body mass index

Body mass index (BMI) was calculated as weight in kilograms divided by height in centimeters squared, height and weight were measured by trained nurses. The interviewees were asked to remove their shoes for the measurement of height. Further, it was categorized as $<18.5 \mathrm{~kg} / \mathrm{m}^{2}$ (underweight), $18.5-25 \mathrm{~kg} / \mathrm{m}^{2}$ (normal weight), $25.0-30 \mathrm{~kg} / \mathrm{m}^{2}$ (overweight), $\geq 30.0+\mathrm{kg} / \mathrm{m}^{2}$ (obesity)[26].

Self-rate health

In this study, self-rated health (SRH) was measured by the multi-item self-rated health measurement scale (SRHMS) developed by Xu Jun et al[21, 22]. The scale is designed according to WHO's definition of health, health is regarded as a multidimensional concept including physical health, mental health and social well-being. The scale reflects the change of health measurement from a single dimension to multidimension and from group to individual. Previous studies have shown that SRHMS could accurately and comprehensively reflect the individual's health status, reliability and validity are acceptable, and have strong adaptability in China[27, 28].The SRHMS consisted of 48 items, the items are divided into 9 dimensions: physical symptom and organic function, daily physical activities, physical mobility, psychosocial symptom and negative emotion, positive emotion, cognitive function, role activity and social adaptability, social resource and social contact, and social support. The 9 dimensions were also categorized into 3 subscales: physical health, mental health and social health. Each of the 48 items has a maximum possible score of 10 and a minimum possible score of 0 , the subscales score and total score maximum possible score of 100 , and the minimum possible score of 0 . The SRHMS is divided into five grades according to the scores: very bad $[0,62.48)$, bad $[62.48,68.49)$, fair $[68.49,80.50)$, good [80.50, $86.50)$, very good $[86.50,100]$.

Other variables

Social demographic factors include gender (male, female), age ( $<40,40-, 60-)$, marriage status (married, others), education (illiterate or semiliterate, primary school, junior school, senior school or above), residence (rural, urban), income (<15000, 15000-, 25000- Year Yuan), health insurance (yes, no).

Health related factors include smoking (yes, no), drinking (yes, no), physical exercise (yes, no), reduce salt intake (yes, no). 
Data analysis

Descriptive statistic methods were used to analyze the characteristics of the study subjects; Chi-square test or t-test were used to compare the difference in categorical and continuous variables; Logistic regression analysis was used to explore the association between BMI and SRHMS among gender differences in hypertensive patients. The data were double entered and verified using EPI Data 6.04, with all data analyzed using SPSS version 16.0 (SPSS, Chicago, Illinois, USA). The level of significance was set at P-values $<0.05$.

\section{Result}

Basic information of the participants

Table 1 shows basic information about the 4390 participants, 1219 participants were hypertensive patients, accounting for $27.8 \%$. Generally speaking, the majority of the hypertensive patients were female $(67.7 \%)$, at the age of $40-50$ (60.7\%), married (92.5\%), primary school education level (58.7\%), residence in the urban (54.7\%), income less than 15000 RMB per year (63.5\%). Among health-related factors, the majority of covered by health insurance (98.3\%), no smoking (82.9\%), no drinking (77.7\%), no physical exercise (64.5\%), reduce salt intake (55.7\%). Age $(P<0.05)$, education $(P<0.001)$, residence $(P<0.05)$, income $(P<0.001)$, smoking $(P<0.001)$, and drinking $(P<0.001)$ was significantly different between hypertensive male and female.

BMI and SRHMS status in hypertensive patients

Table 2 shows the BMI and SRHMS status in hypertensive patients, the average BMI was $26.83 \mathrm{~kg} / \mathrm{m}^{2}$ $(S D=3.77)$, the prevalence of underweight in hypertensive patients was $1.6 \%$, normal weight was $33.0 \%$, overweight was $45.9 \%$, and obese was $19.5 \%$, the proportion of underweight, overweight and obese male was higher than that of female. And the SRHMS of very good, good, fair, bad, and very bad was 20.2 , $15.4,29.1,12.5$, and $22.8 \%$, respectively. The statistical significances were found for SRHMS and physical health in gender, male's SRHMS and physical health was better than female, but not for BMI.

As shown in Table 3, the frequency distribution of SRHMS according to BMI groups, there were significant differences among different body weight groups of SRHMS ( $P=0.009)$, SRHMS in hypertensive patients were better in normal weight groups than the underweight, overweight and obesity groups. Furthermore, there was statistical significance between mental health, physical health and BMI groups.

Association between BMI and SRHMS and its gender difference

We presented our results in two logistic regression models so that we could better understand the association between BMI and SRHMS among gender differences in hypertensive patients (Table 4, Table 5). Table 4 shows the association between BMI and SRHMS among male hypertensive patients, unadjusted model (Model 1) shows that underweight $(\mathrm{OR}=0.23,95 \% \mathrm{CL}=0.06,0.98)$ and obesity $(\mathrm{OR}=2.47,95 \% \mathrm{CL}=1.49,4.11)$ was associated with SRHMS compared with normal weight, when 
controlling for other variables (age, marriage status, education, residence, income, health-related factors), as shown in Model 2, underweight $(\mathrm{OR}=0.20,95 \% \mathrm{CL}=0.05,0.85)$ and obesity $(\mathrm{OR}=1.75,95 \% \mathrm{CL}=1.03$, 2.98) was still statistically significant compared to normal weight. For the female hypertensive patients (Table 5), the association between underweight ( $\mathrm{OR}=0.26,95 \% \mathrm{CL}=0.09,0.76)$, overweight (OR $=0.69,95 \%$ $C L=0.52,0.92)$, obesity $(O R=0.54,95 \% C L=0.37,0.77)$ and $S R H M S$ was still supported after controlling other sociodemographic and health-related variables.

We also found that residence and reduce salt intake were significantly associated with SRHMS for both male and female, the SRHMS of urban residents was better than that of rural residents, and hypertensive patients with reduced salt intake had better SRHMS both male and female.

\section{Discussion}

Gender differences in the association between BMI and SRHMS among hypertensive patients were investigated explicitly in our study. To our knowledge, this is the first study that reports the BMI-SRHMS association among Chinese hypertensive patients. The results showed the different associations between BMI and SRHMS among male and female hypertensive patients. Specifically, this study has the following valuable findings.

Prior studies have found $\mathrm{U}$ shaped relationship between $\mathrm{BMI}$ and $\mathrm{SRH}$, it's different from what we found[24, 29]. After controlling potential confounders, we found that underweight, overweight and obese had a negative impact on female's SRHMS. Underweight had a negative impact on male, but obesity had a positive impact on male's SRHMS. In addition, this study did not find that overweight had a statistically significant effect on male SRHMS.

In recent years, many studies have investigated the obesity-SRH across the globe, and the relationship between underweight and SRH is likely to be ignored. Nevertheless, the impact of lower BMI on health is stronger in developing countries[30,31].Our study found that underweight had a negative effect on SRH which was consistent with prior literature[32-34], it was known that underweight was linked to eating disorders such as anorexia nervosa, or consumptive diseases such as malignant tumors[35].

Generally, overweight and obesity were negatively associated with SRH, previous studies have shown this[23, 36-38]. Moreover, hypertensive patients often have other complications affecting their quality of life and leading to poor overall health, such as diabetes, stroke, cardiovascular diseases[39, 40]. A surprising but interesting finding in our study was that overweight had a negative impact on female's SRHMS after controlling other sociodemographic and health-related variables, but not for male. And obesity had different effects on gender, which had a positive impact on male's SRHMS. After analyzing the causes, female might be more susceptible to body image or weight problems than men, it can be interpreted as the sociocultural context of female's body image, an inherent concept of the personal body weight, such as more discrimination against female with excess body weight at work or in life[41]. From the perspective of Chinese cultural factors, male obesity is a symbol of wealth and status, because only the rich people can afford to eat more and gain weight[42]. It's the opposite of the stigma of female 
obesity in Chinese society. Moreover, considering the components of SRHMS, mental health is an important component of SRHMS, the "Jolly Fat" hypothesis explains this phenomenon in mental health, it suggests that obese people may have lower levels of depression[43]. The hypothesis of "Jolly Fat" was also supported by another study, they found that those who were overweight or obese were more jolly than those who were thinner[44, 45], which was consistent with our research. Accordingly, more targeted in hypertension management and weight management should be considered, including gender-specific intervention strategies.

We also found an association between SRHMS and reduced salt intake in male and female. Rizhao City is near the sea, although most of the residents have received propaganda to reduce the salt intake, due to cultural traditions and habits, the residents consume more salted seafood. The local CDC distributed quantitative salt spoons to residents free of charge and recommended a standard of 6 grams of salt per person per day. We found that hypertensive patients with reduced salt intake had better SRHMS both male and female. Salt intake plays a vital role in regulating blood pressure, moderate and long-term reduction of salt intake in population, which will lower population blood pressure and therefore reduce cardiovascular mortality [46].

This study has several limitations. Firstly, this study was a cross-sectional design, and it may be difficult to confirm the causal relationships of SRHMS and its determina nts. Secondly, SRHMS and hypertensionrelated information were self-reported, leading to the possibility of subjective bias. Thirdly, the relationship between SRHMS and BMI were complex, other diseases may affect SRHMS (cancer, mental illness, metabolic disorders, etc.), nurses asked respondents about their past disease history and excluded them from the study. We considered as many confounders as possible, however, there were some unknown factors. In the follow-up study, we will consider more potential factors to correct possible deviations.

\section{Conclusion}

In this cross-sectional study, we found that the SRHMS of male hypertensive patients was better than female. We also found a gender differences in the association between BMI and SRHMS among patients with hypertension, overweight and obesity had a negative impact on female's SRHMS after adjusting for other influential factors, but not for male. Reducing salt intake can effectively improve SRHMS of hypertensive patients. According to the gender differences in patients with hypertension, more targeted hypertension and weight management should be taken into consideration, including gender-specific intervention strategies.

\section{Abbreviations}

BMI: Body mass index; SRH: Self-rated health; SRHMS: The multiple-item self-rated health measurement scale; 


\section{Declarations}

\section{Acknowledgements}

The authors gratefully acknowledge the contribution of the interviewers and the cooperation of the sampled community health service institutions in the data collection. The authors thank the CDC of Lanshan and Wulian District for their help and support in the data collection.

\section{Ethics approval}

The Ethical Committee of Weifang Medical University School of Public Health and Management approved the study protocol. The investigation was conducted after the informed consents of all participants were obtained.

\section{Funding}

This study was funded by the National Natural Science Foundation of China (71804131 and 71373182)『 and Technical Innovation Team Support Program of Weifang Medical University.

\section{Availability of data and materials}

The data generated during this study are not publicly available, due to the reason that sufficient information is contained to enable readers to identify sampled community health service institutions and contains a large amount of private information of the participants, but a de-identified analytical file is available from the corresponding author on reasonable request.

\section{Competing interests}

None declared.

\section{Authors' contributions}

Zhiqiang Feng and Wenqiang Yin developed the study design. Zhiqiang Feng, Longde Zhou and Zixuan Zhao participated in the analysis and interpretation of the data and drafted the manuscript. All authors contributed to the editing of the manuscript. All authors read and approved the final manuscript.

\section{References}

1. Li Y, Yang L, Wang L, Zhang M, Huang Z, Deng Q, Zhou M, Chen Z, Wang L: Burden of hypertension in China: a nationally representative survey of 174,621 adults. INT J CARDIOL 2017, 227:516-523.

2. Abarca-Gómez L, Abdeen ZA, Hamid ZA, Abu-Rmeileh NM, Acosta-Cazares B, Acuin C, Adams RJ, Aekplakorn W, Afsana K, Aguilar-Salinas CA: Worldwide trends in body-mass index, underweight, 
overweight, and obesity from 1975 to 2016: a pooled analysis of 2416 population-based measurement studies in 128. 9 million children, adolescents, and adults. The Lancet 2017, 390(10113):2627-2642.

3. Kearney P: Global burden of hypertension : analysis of worldwide data. LANCET 2005, 365(9455):217-223.

4. Yang G, Wang Y, Zeng Y, Gao GF, Liang X, Zhou M, Wan X, Yu S, Jiang Y, Naghavi M: Rapid health transition in China, 1990-2010: findings from the Global Burden of Disease Study 2010. LANCET 2013, 381(9882):1987-2015.

5. Li D, Lv J, Liu F, Liu P, Hao M: Hypertension burden and control in mainland China: Analysis of nationwide data 2003-2012. INT J CARDIOL 2015, 184(1):637-644.

6. Silva DAS, Petroski EL, Peres MA: Is high body fat estimated by body mass index and waist circumference a predictor of hypertension in adults? A population-based study., 11(1).

7. Khashayar P, Heshmat R, Qorbani M, Motlagh ME, Aminaee T, Ardalan G, Farrokhi-Khajeh-Pasha Y, Taslimi M, Larijani B, Kelishadi R: Metabolic Syndrome and Cardiovascular Risk Factors in a National Sample of Adolescent Population in the Middle East and North Africa: The CASPIAN III Study. INT J ENDOCRINOL, 2013:1-8.

8. Mehrkash M, Kelishadi R, Mohammadian S, Mousavinasab F, Shafa N: Obesity and metabolic syndrome among representative sample of Iranian adolescents. Southeast Asian J Trop Med Public Health 2012, 43(3):756-763.

9. Zhu YB, Luo XX, Wang Q: [Study on the relationship between body mass index and health-related quality of life in middle-aged or older Chinese adults]. 2009, 30(7):687-691.

10. Haslam DW, James WP: Obesity. 2005, 366(9492):1197.

11. Narkiewicz K: Obesity and hypertension-the issue is more complex than we thought. NEPHROL DIAL TRANSPL 2005, 21(2):264-267.

12. Nyamdorj R, Qiao Q, Derberg SS, Niemi JMP, Zimmet PZ, Shaw JE, Alberti KGMM, Pauvaday VK, Chitson P, Kowlessur S: BMI Compared With Central Obesity Indicators as a Predictor of Diabetes Incidence in Mauritius. 2009.

13. Zhang M, Zhao Y, Wang G, Zhang H, Ren Y, Wang B, Zhang L, Yang X, Han C, Pang C: Body mass index and waist circumference combined predicts obesity-related hypertension better than either alone in a rural Chinese population. SCI REP-UK, 6:31935.

14. Chobanian AV, Bakris GL, Black HR, Cushman WC, Green LA, Izzo Jr JL, Jones DW, Materson BJ, Oparil S, Wright Jr JT: Seventh report of the joint national committee on prevention, detection, evaluation, and treatment of high blood pressure. HYPERTENSION 2003, 42(6):1206-1252.

15. Marja J: What is self-rated health and why does it predict mortality? Towards a unified conceptual model. SOC SCI MED 2009, 69(3):307-316.

16. Holstein BE, Hansen EH, Andersen A, Due P: Self-rated health as predictor of medicine use in adolescence. PHARMACOEPIDEM DR S 2008, 17(2):186-192. 
17. Mossey JM, Shapiro E: Self-rated health: a predictor of mortality among the elderly. AM J PUBLIC HEALTH 1982, 72(8):800-808.

18. Bachmann JM, Goggins KM, Nwosu SK, Schildcrout JS, Kripalani S, Wallston KA: Perceived health competence predicts health behavior and health-related quality of life in patients with cardiovascular disease. PATIENT EDUC COUNS 2016, 99(12):2071-2079.

19. Bauer GF, Huber CA, Jenny GJ, Müller F, Mmig OH: Socioeconomic status, working conditions and self-rated health in Switzerland: explaining the gradient in men and women. INT J PUBLIC HEALTH 2009, 54(1):23-30.

20. Sloan JA, Aaronson N, Cappelleri JC, Fairclough DL, Varricchio C: Assessing the Clinical Significance of Single Items Relative to Summated Scores. Mayo Clinic Proceedings Mayo Clinic 2002, 77(5):479487.

21. Jun XU, Bo LI, Min Yan HU: The study of reliability on self-rated health measurement scale. Chinese Journal of Behavioral Medical Science 2002.

22. Xu Jun GRLY: The Study of Responsiveness on Self-rated Health Measurement Scale (the Revised Version 1.0). Chinese Journal of Health Statistics 2003.

23. Imai K, Gregg EW, Chen YJ, Zhang P, De RN, Williamson DF: The association of BMI with functional status and self-rated health in US adults. OBESITY 2012, 16(2):402-408.

24. Norman P, Fraser L: Self-reported general health and Body Mass Index: a U-shaped relationship? PUBLIC HEALTH 2013, 127(10):938-945.

25. Imai K, Gregg EW, Chen YJ, Zhang P, de Rekeneire N, Williamson DF: The Association of BMI With Functional Status and Self-rated Health in US Adults., 16(2):402-408.

26. Tan K, Consultation WE: Appropriate body-mass index for Asian populations and its implications for policy and intervention strategies. LANCET 2004, 363(9403):157-163.

27. Li F, Chen J, Yu L, Jing Y, Jiang P, Fu X, Wu S, Sun X, Luo R, Kwan H: The Role of Stress Management in the Relationship between Purpose in Life and Self-Rated Health in Teachers: A Mediation Analysis. International Journal of Environmental Research \& Public Health 2016, 13(7):719.

28. Lolokote S, Hidru TH, Li X: Do socio-cultural factors influence college students' self-rated health status and health-promoting lifestyles? A cross-sectional multicenter study in Dalian, China. BMC PUBLIC HEALTH 2017, 17(1):478.

29. Imai K, Gregg EW, Chen YJ, Zhang P, Rekeneire N, Williamson DF: The Association of BMI With Functional Status and Self-rated Health in US Adults. OBESITY 2012, 16(2):402-408.

30. Sauvaget C, Ramadas K, Thomas G, Vinoda J, Thara S, Sankaranarayanan R: Body mass index, weight change and mortality risk in a prospective study in India. INT J EPIDEMIOL 2008, 37(5):9901004.

31. Selvamani Y, Singh P: Socioeconomic patterns of underweight and its association with self-rated health, cognition and quality of life among older adults in India. PLOS ONE 2018, 13(3):e193979. 
32. Wu, Shunquan, Wang, Rui, Zhao, Yanfang, Ma, Xiuqiang, Wu, Meijing: The relationship between selfrated health and objective health status:;a population-based study. BMC PUBLIC HEALTH2013, 13(1):320.

33. Molarius A, Berglund K, Eriksson C, Lambe M, Nordstrã M E, Eriksson HG, Feldman I: Socioeconomic conditions, lifestyle factors, and self-rated health among men and women in Sweden. EUR J PUBLIC HEALTH 2007, 17(2):125-133.

34. Ramin H, Roya K, Nazgol MG, Mohammad-Esmaeil M, Gelayol A, Tahereh A, Hadith R, Hamid A, Shirin $D$, Bagher L: Association between body mass index and perceived weight status with self-rated health and life satisfaction in Iranian children and adolescents: the CASPIAN-III study. Quality of Life Research An International Journal of Quality of Life Aspects of Treatment Care \& Rehabilitation 2015, 24(1):263-272.

35. Wu, Shunquan, Wang, Rui, Zhao, Yanfang, Ma, Xiuqiang, Wu, Meijing: The relationship between selfrated health and objective health status:;a population-based study. BMC PUBLIC HEALTH2013, 13(1):320.

36. Myint PK, Welch AA, Luben RN, Wainwright NW, Surtees PG, Bingham SA, Wareham NJ, Smith RD, Harvey IM, Khaw KT: Obesity indices and self-reported functional health in men and women in the EPIC-Norfolk. OBESITY 2006, 14(5):884-893.

37. Koyanagi A, Moneta MV, Garin N, Olaya B, Ayuso-Mateos JL, Chatterji S, Leonardi M, Sainio P, Galas A, Haro JM: The association between obesity and severe disability among adults aged 50 or over in nine high-income, middle-income and low-income countries: a cross-sectional study. BMJ OPEN 2015, 5(4):e7313.

38. Wang A, Arah OA: Peer Reviewed: Body Mass Index and Poor Self-Rated Health in 49 Low-Income and Middle-Income Countries, By Sex, 2002-2004. PREV CHRONIC DIS 2015, 12.

39. Galenkamp H, Braam AW, Huisman M, Deeg DJH: Somatic Multimorbidity and Self-rated Health in the Older Population. Journals of Gerontology 2011, 66(3):380-386.

40. Gorman BK, Sivaganesan A: The role of social support and integration for understanding socioeconomic disparities in self-rated health and hypertension. SOC SCI MED 2007, 65(5):958-975.

41. Paquette MC, Raine K: Sociocultural context of women's body image. SOC SCI MED 2004, 59(5):1047-1058.

42. Li ZB, Ho SY, Chan WM, Ho KS, Li MP, Leung GM, Lam TH: Obesity and depressive symptoms in Chinese elderly. INT J GERIATR PSYCH 2004, 19(1):68-74.

43. Crisp AH, McGuiness B: Jolly fat: relation between obesity and psychoneurosis in general population. $B M J, 1(6000): 7-9$.

44. You H, Li X, Jing K, Li Z, Cao H, Wang J, Bai L, Gu J, Fan X, Gu H: Association between body mass index and health-related quality of life among Chinese elderly-evidence from a community-based study. BMC PUBLIC HEALTH 2018, 18(1):1174.

45. Muennig P, Lubetkin E, Jia H, Franks P: Gender and the Burden of Disease Attributable to Obesity. AM J PUBLIC HEALTH, 96(9):1662-1668. 
46. He FJ, MacGregor GA: Effect of modest salt reduction on blood pressure: a meta-analysis of randomized trials. Implications for public health., 16(11):761-770.

\section{Tables}

Table 1. Socio-demographic characteristics of study participants in Rizhao City, China, 2019

\begin{tabular}{|c|c|c|c|c|}
\hline \multirow[t]{2}{*}{ Variable } & \multicolumn{2}{|c|}{ Total $(\mathrm{N}=4390)$} & \multicolumn{2}{|c|}{ Hypertensive $(\mathrm{N}=1219)$} \\
\hline & Hypertensive & Others & Male & Female \\
\hline $\mathbf{N}(\%)$ & $1219(27.8)$ & $3171(72.2)$ & $394(32.3)$ & $825(67.7)$ \\
\hline \multicolumn{5}{|l|}{ Age } \\
\hline$<40$ & $66(5.4)$ & $549(17.3)^{* * *}$ & $32(8.1)$ & $34(4.1)^{*}$ \\
\hline $40-$ & $740(60.7)$ & $1956(61.7)$ & $225(57.1)$ & $515(62.4)$ \\
\hline $60-$ & $413(33.9)$ & $666(21.0)$ & $137(34.8)$ & $276(33.5)$ \\
\hline \multicolumn{5}{|l|}{ Marriage status } \\
\hline Married & $1128(92.5)$ & $2923(92.2)$ & $360(91.4)$ & $768(93.1)$ \\
\hline Others & $91(7.5)$ & $248(7.8)$ & $34(8.6)$ & $57(6.9)$ \\
\hline \multicolumn{5}{|l|}{ Education } \\
\hline Illiterate or semiliterate & $409(33.6)$ & $678(21.40)^{* * *}$ & $64(16.2)$ & $345(41.8)^{* * *}$ \\
\hline Primary school & $715(58.7)$ & $1978(62.4)$ & $273(69.3)$ & $442(53.6)$ \\
\hline Junior school & $86(7.1)$ & $423(13.3)$ & $49(12.4)$ & $37(4.5)$ \\
\hline Senior school or above & $9(0.7)$ & $92(2.9)$ & $8(2.1)$ & $1(0.1)$ \\
\hline \multicolumn{5}{|l|}{ Residence } \\
\hline Rural & $552(45.3)$ & $1234(38.9)^{* * *}$ & $158(40.1)$ & $394(47.8)^{*}$ \\
\hline Urban & $667(54.7)$ & $1937(61.1)$ & $236(59.9)$ & $431(52.2)$ \\
\hline \multicolumn{5}{|l|}{ Income (Year Yuan) } \\
\hline$<15000$ & $774(63,5)$ & $1646(51.9)^{* * *}$ & $218(55.3)$ & $556(67.4)^{* * *}$ \\
\hline $15000-$ & $187(15.3)$ & $466(14.7)$ & $69(17.5)$ & $118(14.3)$ \\
\hline $25000-$ & $258(21.2)$ & 1059 (33.4) & $107(27.2)$ & $151(18.3)$ \\
\hline \multicolumn{5}{|l|}{ Health insurance } \\
\hline Yes & 1198 (98.3) & 3104 (97.9) & $386(98.0)$ & $812(98.4)$ \\
\hline No & $21(1.7)$ & $67(2.1)$ & $8(2.0)$ & $13(1.6)$ \\
\hline \multicolumn{5}{|l|}{ Smoking } \\
\hline Yes & $208(17.1)$ & $535(16.9)$ & $157(39.8)$ & $51(6.2)^{* * *}$ \\
\hline No & 1011 (82.9) & $2636(83.1)$ & $237(60.2)$ & $774(93.8)$ \\
\hline \multicolumn{5}{|l|}{ Drinking } \\
\hline Yes & $272(22.3)$ & $664(20.9)$ & $188(47.7)$ & $84(10.2)^{* * *}$ \\
\hline No & $947(77.7)$ & 2507 (79.1) & $206(52.3)$ & $741(89.8)$ \\
\hline \multicolumn{5}{|l|}{ Physical exercise } \\
\hline Yes & $433(35.5)$ & $1143(36.0)$ & $152(38.6)$ & $281(34.1)$ \\
\hline No & $786(64.5)$ & $2028(64.0)$ & $242(61.4)$ & $544(65.9)$ \\
\hline \multicolumn{5}{|l|}{ Reduce salt intake } \\
\hline Yes & $679(55.7)$ & $1792(56.5)$ & $214(54.3)$ & $465(56.4)$ \\
\hline No & $540(44.3)$ & 1379 (43.5) & $180(45.7)$ & $369(43.6)$ \\
\hline
\end{tabular}

$* P<0.05$

$* * P<0.01$

$* * * P<0.001$ 
Table 2. BMI and SRHMS status in hypertensive patients in Rizhao City, China, 2019

\begin{tabular}{|c|c|c|c|c|}
\hline Variable & Total & Male & Female & $P$ \\
\hline N (\%) & $1219(100)$ & $394(32.3)$ & $825(67.7)$ & \\
\hline BMI (Mean \pm SD) & $26.83 \pm 3.77$ & $26.73 \pm 3.80$ & $26.88 \pm 3.76$ & 0.507 \\
\hline BMI & & & & 0.681 \\
\hline Underweight $(<18.5)$ & $20(1.6)$ & $7(1.8)$ & $13(1.6)$ & \\
\hline Normal weight (18.5-25.0) & $402(33.0)$ & $122(31.0)$ & $280(33.9)$ & \\
\hline Overweight (25.0-30.0) & $559(45.9)$ & $182(46.1)$ & $377(45.7)$ & \\
\hline Obesity (>30) & $238(19.5)$ & $83(21.1)$ & $155(18.8)$ & \\
\hline SRHMS & & & & 0.009 \\
\hline Very good & $246(20.2)$ & $98(24.9)$ & $148(17.9)$ & \\
\hline Good & $188(15.4)$ & $64(16.2)$ & $124(15.0)$ & \\
\hline Fair & $355(29.1)$ & $118(29.9)$ & $237(28.8)$ & \\
\hline Bad & $152(12.5)$ & $41(10.4)$ & $111(13.5)$ & \\
\hline Very bad & $278(22.8)$ & $73(18.5)$ & $205(24.8)$ & \\
\hline Physical health & & & & 0.002 \\
\hline Very good & $290(23.8)$ & $110(27.8)$ & $180(21.8)$ & \\
\hline Good & $206(16.9)$ & $83(21.1)$ & $123(14.9)$ & \\
\hline Fair & $353(29.0)$ & $100(25.4)$ & $253(30.7$ & \\
\hline Bad & $107(8.8)$ & $29(7.4)$ & $78(9.5)$ & \\
\hline Very bad & $263(21.6)$ & $72(18.3)$ & $191(23.2)$ & \\
\hline Mental health & & & & 0.096 \\
\hline Very good & $318(26.1)$ & $116(29.4)$ & $202(24.5)$ & \\
\hline Good & $144(11.8)$ & 47 (11.9) & $97(11.8)$ & \\
\hline Fair & $237(19.4)$ & $83(21.1)$ & $154(18.7)$ & \\
\hline Bad & $98(8.0)$ & $32(8.1)$ & $66(8.0)$ & \\
\hline Very bad & $422(34.6)$ & $116(29.4)$ & $306(37.1)$ & \\
\hline Social health & & & & 0.122 \\
\hline Very good & 321 (26.3) & $115(29.2)$ & $206(25.0)$ & \\
\hline Good & $132(10.8)$ & 39 (9.9) & 93 (11.3) & \\
\hline Fair & 339 (27.8) & 118 (29.9) & $221(26.8)$ & \\
\hline Bad & 153 (12.6) & 49 (12.4) & $104(12.6)$ & \\
\hline Very bad & $274(22.5)$ & $73(18.5)$ & $201(24.4)$ & \\
\hline
\end{tabular}

Table 3 The frequency distribution of SRHMS according to BMI groups in hypertensive patients 


\begin{tabular}{|c|c|c|c|c|c|}
\hline \multirow[t]{2}{*}{ Variable } & \multicolumn{4}{|c|}{ BMI groups } & \multirow[t]{2}{*}{$P$} \\
\hline & Underweight & Normal weight & Overweight & Obese & \\
\hline $\mathrm{N}(\%)$ & $20(1.6)$ & $402(33.0)$ & $559(45.9)$ & $238(19.5)$ & \\
\hline SRHMS & & & & & 0.012 \\
\hline Very good & $2(10.0)$ & $96(23.9)$ & $97(17.4)$ & $51(21.4)$ & \\
\hline Good & $2(10.0)$ & $64(15.9)$ & $77(13.8)$ & 45 (18.9) & \\
\hline Fair & $2(10.0)$ & $111(27.6)$ & $179(32.0)$ & $63(26.5)$ & \\
\hline Bad & $3(15.0)$ & $48(11.9)$ & $75(13.4)$ & $26(10.9)$ & \\
\hline Very bad & $11(55.0)$ & $83(20.6)$ & $131(23.4)$ & $53(22.3)$ & \\
\hline Physical health & & & & & 0.024 \\
\hline Very good & $3(15.0)$ & $109(27.1)$ & $126(22.5)$ & $52(21.8)$ & \\
\hline Good & $2(10.0)$ & $68(16.9)$ & $86(15.4)$ & $52(21.8)$ & \\
\hline Fair & $7(35.0)$ & $112(27.9)$ & $167(29.9)$ & $67(28.2)$ & \\
\hline Bad & $1(5.0)$ & $30(7.5)$ & $55(9.8)$ & $22(9.2)$ & \\
\hline Very bad & $7(35.0)$ & $83(20.6)$ & $125(22.4)$ & $45(18.9)$ & \\
\hline Mental health & & & & & 0.005 \\
\hline Very good & $2(10.0)$ & $124(30.8)$ & $122(21.8)$ & $70(29.4)$ & \\
\hline Good & $1(5.0)$ & $50(12.4)$ & $63(11.3)$ & $30(12.6)$ & \\
\hline Fair & $2(10.0)$ & $81(20.1)$ & $115(20.6)$ & $39(16.4)$ & \\
\hline Bad & $3(15.0)$ & $20(5.0)$ & $56(10.0)$ & $19(8.0)$ & \\
\hline Very bad & $12(60.0)$ & $127(31.6)$ & $203(36.3)$ & $80(33.6)$ & \\
\hline Social health & & & & & 0.390 \\
\hline Very good & $2(10.0)$ & $111(27.6)$ & $141(25.2)$ & $67(28.2)$ & \\
\hline Good & $2(10.0)$ & 39 (9.7) & $63(11.3)$ & $28(11.8)$ & \\
\hline Fair & $4(20.0)$ & $110(27.4)$ & $150(26.8)$ & $75(31.5)$ & \\
\hline Bad & $4(20.0)$ & $52(12.9)$ & 75 (13.4) & $22(9.2)$ & \\
\hline Very bad & $8(40.0)$ & $90(22.4)$ & $130(23.3)$ & 46 (19.3) & \\
\hline
\end{tabular}

Table 4 Association of BMI and SRHMS among male patients with hypertension 


\begin{tabular}{|c|c|c|c|c|c|c|}
\hline \multirow[t]{2}{*}{ Variable } & \multicolumn{3}{|c|}{ Model 1 (No covariates) } & \multicolumn{3}{|c|}{ Model 2 (Covariates) } \\
\hline & $P$ & OR & OR 95\% CL & $P$ & OR & OR 95\% CL \\
\hline \multicolumn{7}{|l|}{$\overline{\mathrm{BMI}}$} \\
\hline Normal (18.5-25.0) & & 1.0 & & & 1.0 & \\
\hline Underweight $(<18.5)$ & 0.046 & 0.23 & $0.06-0.98$ & 0.030 & 0.20 & $0.05-0.85$ \\
\hline Overweight (25.0-30.0) & 0.500 & 0.87 & $0.58-1.31$ & 0.138 & 0.72 & $0.47-1.11$ \\
\hline Obesity (>30) & 0.001 & 2.47 & $1.49-4.11$ & 0.038 & 1.75 & $1.03-2.98$ \\
\hline \multicolumn{7}{|l|}{ Age } \\
\hline$<40$ & & & & & 1.0 & \\
\hline $40-$ & & & & 0.056 & 0.51 & $0.25-1.02$ \\
\hline $60-$ & & & & 0.004 & 0.34 & $0.16-0.71$ \\
\hline \multicolumn{7}{|l|}{ Marriage status } \\
\hline Married & & & & & 1.0 & \\
\hline Others & & & & 0.010 & 0.41 & $0.21-0.81$ \\
\hline \multicolumn{7}{|l|}{ Education } \\
\hline Illiterate or semiliterate & & & & & 1.0 & 1.0 \\
\hline Primary school & & & & 0.106 & 1.55 & $0.91-2.63$ \\
\hline Junior school & & & & 0.342 & 1.41 & $0.7-2.84$ \\
\hline Senior school or above & & & & 0.231 & 8.52 & $2.26-12.04$ \\
\hline \multicolumn{7}{|l|}{ Residence } \\
\hline Rural & & & & & 1.0 & \\
\hline Urban & & & & 0.004 & 1.79 & $1.21-2.66$ \\
\hline \multicolumn{7}{|l|}{ Income (Year Yuan) } \\
\hline$<15000$ & & & & & 1.0 & \\
\hline $15000-$ & & & & 0.053 & 1.66 & $0.99-2.78$ \\
\hline $25000-$ & & & & 0.192 & 1.34 & $0.86-2.1$ \\
\hline \multicolumn{7}{|l|}{ Health insurance } \\
\hline No & & & & & 1.0 & \\
\hline Yes & & & & 0.011 & 5.9 & $1.51-23.03$ \\
\hline \multicolumn{7}{|l|}{ Smoking } \\
\hline No & & & & & 1.0 & \\
\hline Yes & & & & 0.845 & 1.04 & $0.71-1.52$ \\
\hline \multicolumn{7}{|l|}{ Drinking } \\
\hline No & & & & & 1.0 & \\
\hline Yes & & & & 0.083 & 0.71 & $0.49-1.05$ \\
\hline \multicolumn{7}{|l|}{ Physical exercise } \\
\hline No & & & & & 1.0 & \\
\hline Yes & & & & 0.669 & 1.09 & 0.74-1.59 \\
\hline \multicolumn{7}{|l|}{ Reduce salt intake } \\
\hline No & & & & & 1.0 & \\
\hline Yes & & & & 0.203 & 0.79 & $0.54-1.14$ \\
\hline
\end{tabular}

Table 5 Association of BMI and SRHMS among female patients with hypertension 


\begin{tabular}{|c|c|c|c|c|c|c|}
\hline \multirow[t]{2}{*}{ Variable } & \multicolumn{3}{|c|}{ Model 1 (No covariates) } & \multicolumn{3}{|c|}{ Model 2 (Covariates) } \\
\hline & $P$ & $\overline{\mathrm{OR}}$ & OR 95\% CL & $P$ & OR & OR 95\% CL \\
\hline \multicolumn{7}{|l|}{ BMI } \\
\hline Normal (18.5-25.0) & & \multicolumn{2}{|l|}{1.0} & & \multicolumn{2}{|l|}{1.0} \\
\hline Underweight $(<18.5)$ & 0.004 & 0.21 & $0.07-0.60$ & 0.013 & 0.26 & $0.09-0.76$ \\
\hline Overweight (25.0-30.0) & 0.010 & 0.70 & $0.53-0.92$ & 0.012 & 0.69 & $0.52-0.92$ \\
\hline Obesity $(>30)$ & 0.002 & 0.57 & $0.40-0.81$ & 0.001 & 0.54 & $0.37-0.77$ \\
\hline \multicolumn{7}{|l|}{ Age } \\
\hline$<40$ & & & & \multicolumn{3}{|c|}{1.0} \\
\hline $40-$ & & & & 0.549 & 0.82 & $0.44-1.55$ \\
\hline $60-$ & & & & 0.352 & 0.73 & $0.38-1.42$ \\
\hline \multicolumn{7}{|l|}{ Marriage status } \\
\hline Married & & & & \multicolumn{3}{|c|}{1.0} \\
\hline Others & & & & 0.199 & 0.72 & 0.44-1.19 \\
\hline \multicolumn{7}{|l|}{ Education } \\
\hline Illiterate or semiliterate & & & & \multicolumn{3}{|c|}{1.0} \\
\hline Primary school & & & & 0.008 & 1.45 & $1.1-1.91$ \\
\hline Junior school & & & & 0.001 & 3.07 & $1.57-5.98$ \\
\hline Senior school or above & & & & 0.121 & 1.43 & $0.71-2.88$ \\
\hline \multicolumn{7}{|l|}{ Residence } \\
\hline Rural & & & & \multicolumn{3}{|c|}{1.0} \\
\hline Urban & & & & 0.001 & 2.18 & $1.67-2.86$ \\
\hline \multicolumn{7}{|l|}{ Income (Year Yuan) } \\
\hline$<15000$ & & & & \multicolumn{3}{|c|}{1.0} \\
\hline $15000-$ & & & & 0.199 & 1.28 & $0.88-1.85$ \\
\hline $25000-$ & & & & 0.008 & 1.59 & $1.13-2.25$ \\
\hline \multicolumn{7}{|l|}{ Health insurance } \\
\hline No & & & & \multicolumn{3}{|c|}{1.0} \\
\hline Yes & & & & 0.274 & 1.75 & $0.64-4.74$ \\
\hline \multicolumn{7}{|l|}{ Smoking } \\
\hline No & & & & \multicolumn{3}{|c|}{1.0} \\
\hline Yes & & & & 0.853 & 0.95 & $0.56-1.61$ \\
\hline \multicolumn{7}{|l|}{ Drinking } \\
\hline No & & & & \multicolumn{3}{|c|}{1.0} \\
\hline Yes & & & & 0.381 & 1.2 & $0.79-1.82$ \\
\hline \multicolumn{7}{|l|}{ Physical exercise } \\
\hline No & & & & \multicolumn{3}{|c|}{1.0} \\
\hline Yes & & & & 0.472 & 0.91 & $0.7-1.18$ \\
\hline \multicolumn{7}{|l|}{ Reduce salt intake } \\
\hline No & & & & & 1.0 & \\
\hline Yes & & & & 0.020 & 0.74 & $0.58-0.95$ \\
\hline
\end{tabular}

Figures 


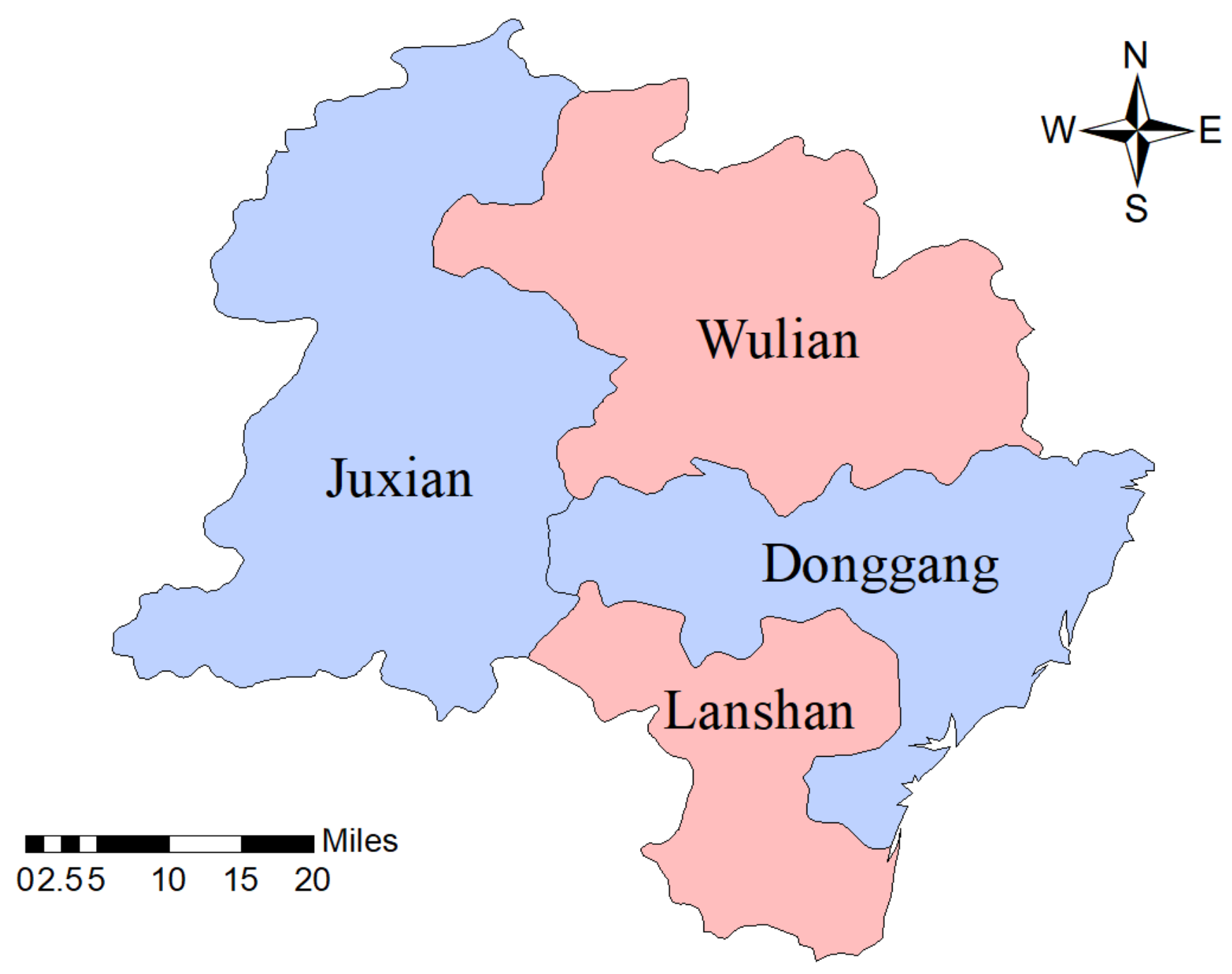

\section{Figure 1}

Location of the study sites in Rizhao City, Shandong Province. Note: The designations employed and the presentation of the material on this map do not imply the expression of any opinion whatsoever on the part of Research Square concerning the legal status of any country, territory, city or area or of its authorities, or concerning the delimitation of its frontiers or boundaries. This map has been provided by the authors.

\section{Supplementary Files}

This is a list of supplementary files associated with this preprint. Click to download.

- SRHMS.docx 